Puspita Dewi Wulaningrum

U niversitas M uhammadiyah Yogyakarta

Jl. Brawijaya, Tamantirto, K asihan,

Bantul, 55183.Telp (0274) 387656

puspita@umy.ac.id

\section{Pengembangan Kawasan Wisata Berbasis Partisipasi Masyarakat Lokal di Koripan 1 Dlingo}

https:/ / doi.org/ 10.18196/ bdr.6240

\begin{abstract}
Koripan 1 in Dlingo has tourism potential that can be developed to improve people's economy, there is water springs from sendang Umbul Ndeso and petilasan Gunung Pasar. In addition, because the majority of people's livelihood are farmers, the results of agricultural processing can also be used as a means of supporting the tourist area. This activity aims to develop the potential tourist area in Koripan 1 which is expected to be an alternative income residents so that the economy increases. The method used is the analysis of village-based tourism development process based on local community participation then reduced to the steps of village development. The results and implications of this activity include the design of tourism objects Umbul Ndeso and petilasan Gunung Pasar, development of early stage of the form of gazebo, street lighting and road directions, training for the community related to improving the quality of farm produce and licensing P-IRT, and marketing through online media. The conclusion of this activity is the development program of tourist area of Koripan 1 has assisted in building the tourist village as well as providing direction for sustainable development step for the community. This activity has also provided education for the citizens about the importance of quality and licensing for food processing business of agricultural products.
\end{abstract}

Keywords: Tourism, Local Community Participation, Processed Agricultural Products

\section{PENDAHULUAN}

Kecamatan Dlingo merupakan salah satu kecamatan di Kabupaten Bantul Propinsi D aerah Istimewa Yogyakarta dengan topografi wilayah kecamatan D lingo hampir secara keseluruhan berbukit-bukit. M ata pencaharian utama warga kecamatan D lingo meliputi pertanian, perternakan, dan perdagangan. $N$ amun pada beberapatahun terakhir, kawasan D lingo mulai mengembangkan potensi lain untuk meningkatkan perekonomian mereka. Panorama alam perbukitan yang asri dan jarang ditemui di kotakota lain ternyata dapat menjadi daya tarik wisatawan yang berimbas pada meningkatnya pen dapatan masyarakat.

Dusun Koripan 1 merupakan salah satu dari 10 dusun di desa Dlingo yang memiliki karakteristik serupa dengan daerah Dlingo lain yaitu berada di dataran tinggi dengan 
luas wilayah pedusunan 92,1 $\mathrm{Ha}$. M ata pencaharian utama sebagian besar warga saat ini adalah pertanian. H asil panen para petani umumnya berupa padi saat musim penghujan, tanaman palawija seperti jagung dan kedelai, serta tanaman-tanaman obat seperti jahe merah dan bawang-bawangan. Para petani di dusun Koripan 1 ditunjang dengan adanya Gapoktan yang dikoordinir antar RT dengan ketua RT sebagai Koordinatornya. Sayangnya, penghasilan sebagai petani belum mampu mengembangkan desa sebagai desa berkemajuan. Masyarakat perlu menggali potensi lain untuk memajukan desa mereka sehingga dapat meningkatkan perekonomian masyarakat.

Pendapatan warga sebenarnya dapat ditingkatkan dengan memanfaatkan dan mengelola potensi pariwisata yang dimiliki dusun Koripan 1. Pariwisata merupakan aktivitas wisatawan ke suatu tempat tujuan wisata di luar keseharian dan lingkungan tempat tinggal untuk melakukan persinggahan sementara waktu dari tempat tinggal (Zakaria \& Suprihardjo, 2014). A danya wisatawan yang berkunjung tentunya memberikan pemasukan bagi daerah yang memiliki lokasi wisata.

Dusun Koripan 1 memiliki potensi wisata yang tidak kalah dari potensi wisata alam Kecamatan Dlingo lain yaitu adanya obyek wisata Petilasan G unung Pasar dan adanya mata air bersih atau sendang yang mereka beri nama U mbul N deso. Lokasi Gunung Pasar dapat ditempuh melalui jalan sisi kanan kantor Kecamatan D lingo sekitar 2 Kilometer. Puncak Gunung Pasar dapat dicapai hanya dengan melalui jalan setapak dengan jarak tempuh sekitar 700 meter. G unung A gung memiliki nilai budaya yang cukup kuat karena dipercaya memiliki pengaruh terhadap sejarah kerajaan M ataram. G unungA gung merupakan tempat bertemunya Ki A geng $G$ iring di saat mengejar Ki A geng Pemanahan. Selain memiliki nilai historikal yang kuat, G unung Pasar memiliki pemandangan yang sejuk dan asri khas pedesaan yang menjadi daya tarik tersendiri bagi pengunjung.

Tempat wisata lain yang terdapat di Dusun Koripan 1 yaitu Sendang U mbul N deso. Sendang ini merupakan sumber air bagi warga Dusun Koripan 1 yang berasal dari aliran mata air pada dusun tersebut. Lokasinya berada di lembah antara beberapa bukit kecil dan dikelilingi pepohonan yang rindang. Tempatnya yang asri, sumber mata air yang jernih dan udara yang sejuk menjadi kunci daya tarik Sendang U mbul $\mathrm{N}$ deso ini.

Potensi-potensi wisata yang dimiliki D usun Koripan 1 sayangnya belum dikembangkan secara maksimal. Padahal jika dikelola dengan baik, potensi wisata tersebut dapat memberikan sumbangsih yang besar bagi peningkatan pendapatan masyarakat sekitar sekaligus membantu masyarakat untuk dapat membangun perekonomian secara mandiri. Kurangnya sarana wisata juga merupakan faktor penghambat berkembangnya kawasan 


\section{3}

pariwisata di dusun Koripan 1. Sarana wisata merupakan kelengkapan daerah tujuan wisata yang diperlukan untuk melayani kebutuhan wisatawan dalam menikmati perjalanan wisatanya (D wiputra, 2013). A pabila sarana wisata kurang memadai, hal ini berdampak pada kurangnya minat wisatawan untuk berkunjung ke lokasi wisata. O leh karena itu, kelengkapan saran wisata penting untuk diperhatikan .

Potensi lain yang perlu untuk dikemban gkan untuk pengembangan lokasi wisata adalah penyediaan fasilitas oleh-oleh khas daerah. Tingkat kesadaran masyarakat akan perlunya berinovasi untuk menjual hasil panen bukan hanya secara mentah sebenarnya sudah mulai terbentuk. Masyarakat mulai berupaya dan berkreasi untuk meningkatkan nilai jual hasil panen dengan mengolah hasil panen menjadi produk olahan makanan yang dapat dijadikan oleh-oleh khas D lingo. A dapun oleh-oleh khas Dlingo adalah olahan hasil panen jagung menjadi bakpia jagung. Keberadaan produk bakpia jagung ini juga mampu menyerap tenaga kerja dari ibu rumah tangga di daerah tersebut. Sayangnya pemasaran produk bakpia jagung belum maksimal. Bakpia jagung jarang diproduksi karena masyarakat luas belum mengenal adanya makanan khas asal Koripan 1 ini.

O leh karena itu, kegiatan ini bertujuan untuk mengembangkan potensi kawasan wisata di Koripan 1 yang diharapkan dapat menjadi alternatif mata pen caharian warga sehingga perekonomian masyarakat lebih meningkat. Kegiatan ini berusaha pula melibatkan partisipasi masyarakat lokal ke dalam semua tahap mulai dari perencanaan, pengembangan, implementasi, sampai pengawasan agar muncul kesadaran masyarakat serta rasa memiliki dan rasa bertanggung jawab terhadap program pen gemban gan kawasan wisata Koripan 1 Dlingo.

\section{METODE PELAKSANAAN}

Penerapan pengembangan pariwisata berbasis partisipasi masyarakat lokal menyaratkan partisipasi masyarakat sepenuhnya ke dalam program pengembangan kawasan wisata yang ditargetkan untuk dipecahkan masalahnya. Tahapan itu meliputi tahap perencanaan, tahap implementasi, dan tahap pengawasan.

Tahap 1: Perencanaan

Keterlibatan masyarakat dalam tahap perencanaan adalah masyarakat dilibatkan dalam mengidentifikasi masalah, penentuan tujuan dan pengambilan keputusan terkait pengembangan kawasan wisata (D ewi, Fandeli, \& Baiquni, 2013). Pada tahap ini, Tim melakukan observasi di desa Koripan 1 Dlingo serta menjalin komunikasi dengan pemerintah desa dan perwakilan warga masyarakat. Selanjutnya tim berdiskusi tentang 
permasalahan yang ada serta potensi yang dimiliki desa kepada masyarakat dengan cara membuat forum diskusi dengan warga dan diskusi personal dengan mengunjungi tokohtokoh masyarakat serta penggiat desa. Langkah terakhir pada tahap ini adalah tim dan masyarakan mengambil keputusan akan langkah-langkah yang akan diterapkan untuk memecahkan permasalahan yang telah dipetakan.

Tahap 2: Implementasi

Tahap implementasi ini melibatkan masyarakat dalam pengelolaan usaha-usaha pariwisata (D ewi et al., 2013). Pada tahapan ini tim beserta warga dan pemerintah desa menentukan langkah teknis sebagai solusi pemecahan masalah kemudian tim dan masyarakat secara bersama-sama melaksanakan solusi yang telah ditentukan.

Tahap 3: Pengawasan

Kontrol terhadap pelaksanaan program harus diberikan kepada masayarakat sepenuhnya (Sidiq \& Resnawaty, 2012). Pada tahap ini, tim menyerahkan pengawasan pelaksanaan dan keberlanjutan program kepada masyarakat seutuhnya. Tim hanya berfungsi sebagai pendamping masayarakat dalam pengawasan program.

\section{HASIL DAN PEMBAHASAN}

\section{Tahap 1: Perencanaan}

Tahapan ini bertujuan untuk memetakan masalah utama yang akan diangkat untuk mengembangkan kawasan wisata di dusun Koripan 1 D lingo. Tahapan ini dimulai dengan observasi lokasi dan diskusi dari tim dengan warga desa dan pemerintah desa. $\mathrm{H}$ asil dari tahap perencanaan ini adalah terpetakan masalah utama dusun dengan analisis SW OT.

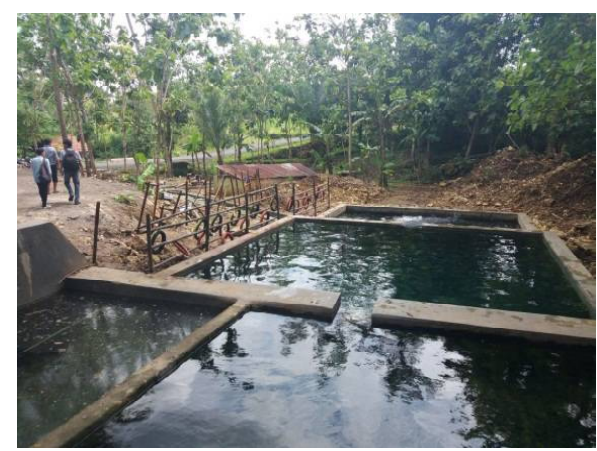

Gambar 1. Observasi sendang

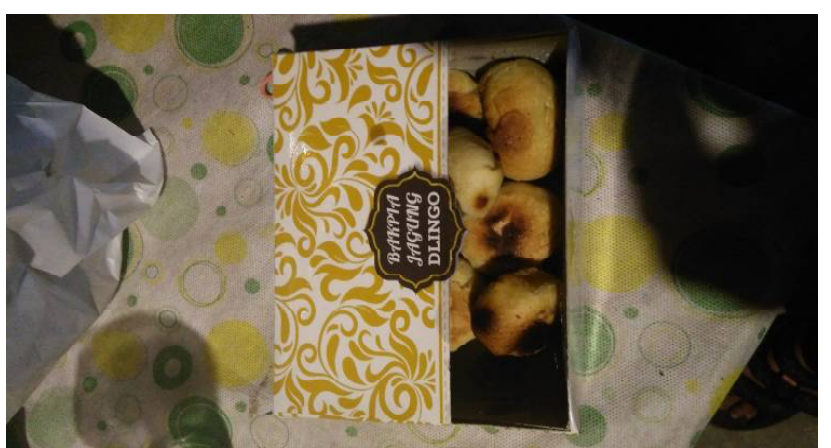

Gambar 2. Produk olahan pertanian: Bakpia J agung 


\section{5}

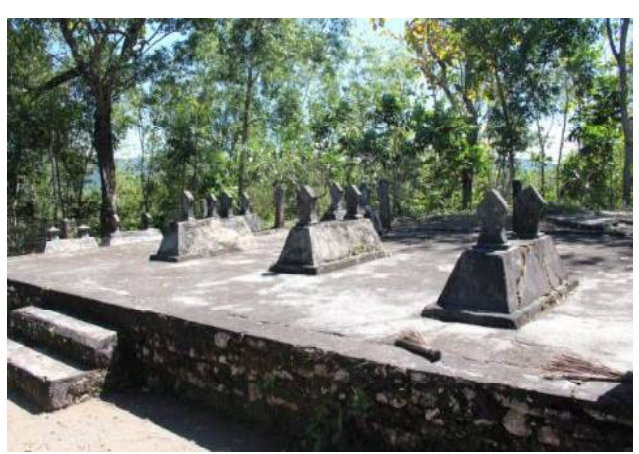

Gambar 3. Observasi petilasan

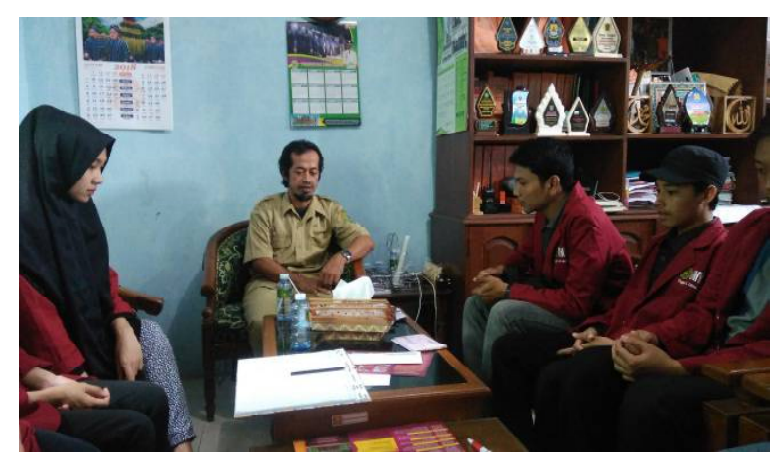

Gambar 4. Diskusi dengan pemerintah desa

Tabel 1. Analisis SWOT

\begin{tabular}{|c|c|c|}
\hline \multirow[b]{2}{*}{ INTERNAL } & STRENGTH (KEKUATAN) & WEAKNESS (KELEM AHAN) \\
\hline & $\begin{array}{l}\text { 1. Keberadaan mata air bersih yang saat ini } \\
\text { telah dibuat bak penampungan. } \\
\text { 2. Adanya petilasan yang diberi nama } \\
\text { Gunung Pasar. Petilasan ini memiliki } \\
\text { sejarah yang berkaitan erat dengan } \\
\text { Kerajaan M ataram yaitu terkait dengan } \\
\text { tempat bertemunya Ki Ageng Giring dan } \\
\text { Ki Ageng Pemanahan } \\
\text { 3. Hasil pertanian masyarakat cukup } \\
\text { melimpah dan dibuat olahan makanan } \\
\text { yang unik dan beragam, khususnya } \\
\text { olahan jagung menjadi bakpia jagung }\end{array}$ & $\begin{array}{l}\text { 1. Pemanfaatan mata air bersih baru digunakan } \\
\text { untuk mengairi sawah dan untuk kegiatan } \\
\text { sehari-hari masyarakat seperti untuk mandi } \\
\text { dan mencuci } \\
\text { 2. Lokasi petilasan tidak terawat dan susah } \\
\text { diakses karena masih ditumbuhi tanaman liar } \\
\text { 3. Pemasaran belum maksimal dan belum } \\
\text { memiliki izn P-IRT }\end{array}$ \\
\hline \multirow[b]{2}{*}{ EKSTERNAL } & OPPORTUNITIES (KESEM PATAN) & THREAT (TANTANGAN) \\
\hline & $\begin{array}{l}\text { 1. Kawasan Dlingo saat ini cukup terkenal } \\
\text { dengan wisata-wisata alamnya } \\
\text { 2. Dukungan dari pemerintah daerah } \\
\text { untuk mengembangkan kawasan wisata }\end{array}$ & $\begin{array}{l}\text { 1. Pembangunan wisata alam Dlingo di daerah } \\
\text { lain sudah sangat berkembang menyebabkan } \\
\text { persaingan yang sangat ketat } \\
\text { 2. Masih banyak wisatawan yang tidak } \\
\text { mengetahui keberadaan Sendang Umbul } \\
\text { Ndeso dan Petilasan Gunung Pasar di } \\
\text { Koripan } 1\end{array}$ \\
\hline
\end{tabular}

2. Tahap 2: Implementasi

Tahap implementasi merupakan penentuan solusi dari analisis SWOT yang telah dibuat pada tahap perencanaan. Pada tahap ini, desain pengembangan daerah wisata Petilasan G unung Pasar dan Sendang U mbul N deso dibuat, pembangunan awal daerah wisata dilakukan, serta diadakan pelatihan dari ahli tentang sertifikasi makanan olahan pertanian.

\section{a. D esain rancang bangun daerah wisata Sendang U mbul N deso dan Petilasan Gunung}

\section{Pasar}

D esain tersebut akan digunakan sebagai grand design pembangunan lokasi wisata dari pembangunan awal sampai pembangunan akhir. Proses pembuatan desain rancang bangun daerah wisata Sendang U mbul N deso dan Petilasan Gunung Pasar dilakukan 
antara anggota Tim yang memiliki keahlian khusus di bidang teknik sipil dengan terus menerus berdiskusi kepada penggiat masyarakat. H asil desain perencan aan lokasi wisata Sendang U mbul N deso adalah Gambar 1, sedangkan Gambar 2 merupakan desain perencanaan lokasi wisata Petilasan G unung Pasar.

\section{b. Pembangunan berkala pada daerah wisata}

Pembangunan ini dilakukan dalam bentuk perbaikan lokasi dan penambahan fasilitas untuk menciptakan kawasan wisata yang ideal. Perwujudan desain rancang bangun tempat wisata dilakukan dengan pembangunan tahap awal di lokasi Sendang dilakukan dengan pembangunan bangunan-bangunan utama bagi tempat wisata. Kolam sendang, mushola, dan kamar mandi sudah dibangun oleh warga sebelumnya. O leh karena itu, pembangunan kali ini berfokus pada pembuatan gazebo dan perbaikan lokasi parkir di area wisata.

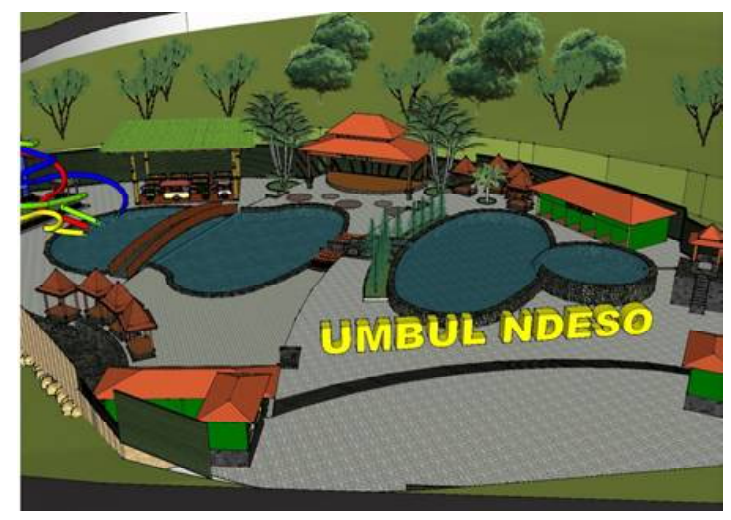

Gambar 5. Desain Rancang Bangun Sendang Umbul Ndeso

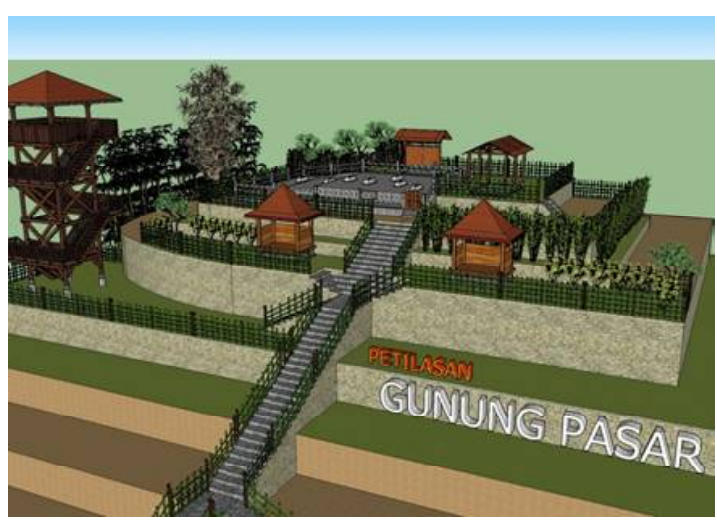

Gambar 6. Desain Rancang Bangun Petilasan Gunung Pasar

Sedangkan untuk Petilasan G unung Pasar, belum ada perbaikan yang cukup signifikan dari warga sebelumnya meskipun lokasi tersebut potensial sebagai tempat wisata. O leh karena itu, pembangunan awal masih berupa pengukuran lokasi, pembukaan jalan menuju petilasan, penerangan jalan, serta pengecatan.

\section{c. Sertifikasi makanan olahan pertanian yang dijual sebagai oleh-oleh khas daerah}

Adanya program ini merupakan wujud dari usaha tim membekali masyarakat agar memiliki pengetahuan terkait peningkatan kualitas hasil tani serta pengurusan P-IRT. Tim mengadakan dua kali pelatihan sebagai bekal awal bagi masyarakat terutama kelompok tani agar kedepannya masyarakat lebih mandiri. Pelatihan pertama berupa penyuluhan pertanian. Pelatihan ini dilaksanakan untuk meningkatkan kualitas hasil 


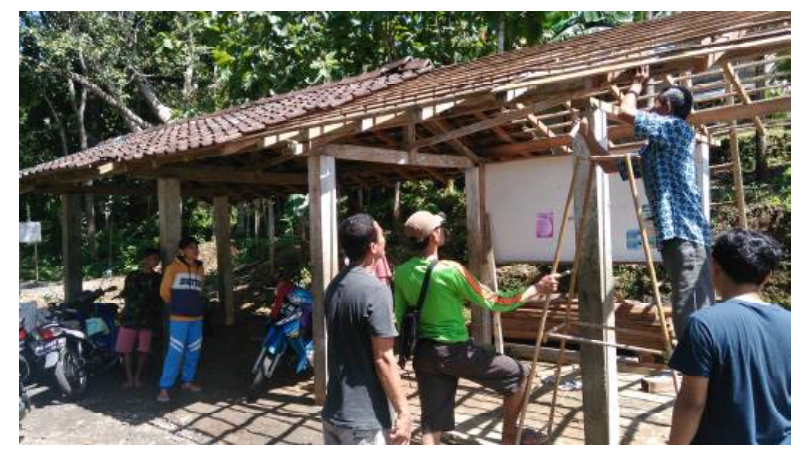

Gambar 7. Pembangunan lokasi parkir bersama masyarakat

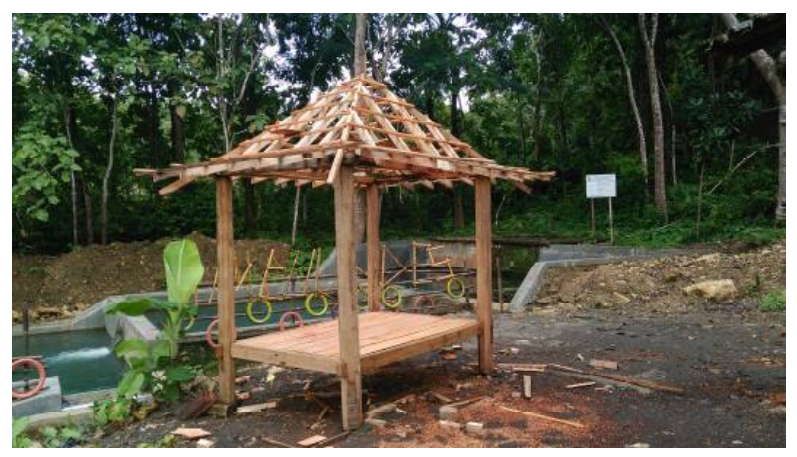

Gambar 9. Gazebo sebelum finishing

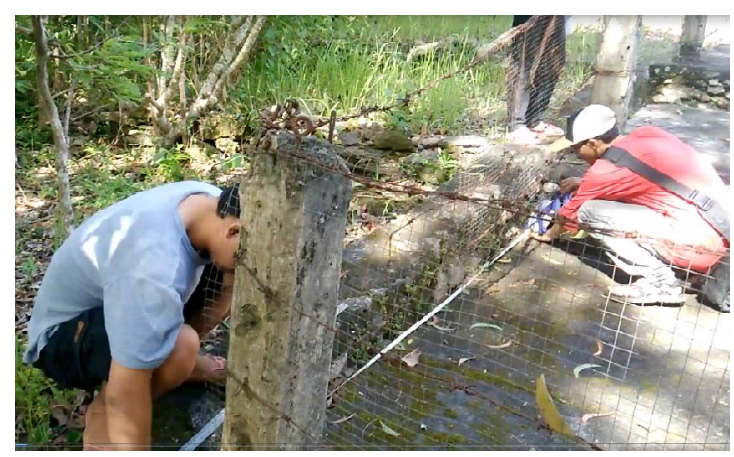

Gambar 11. Pengukuran Petilasan

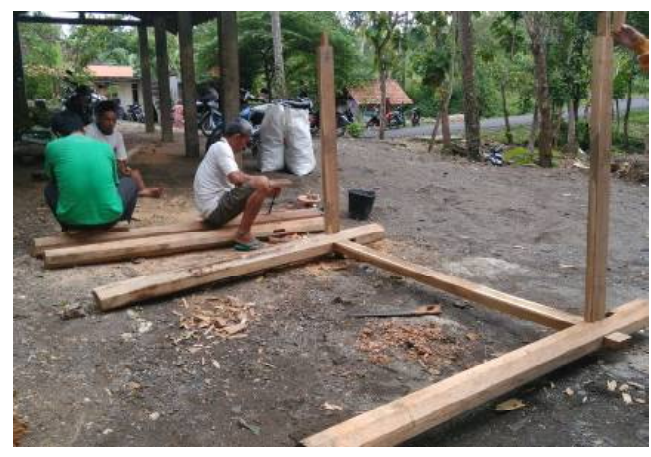

Gambar 8. Proses pembangunan gazebo

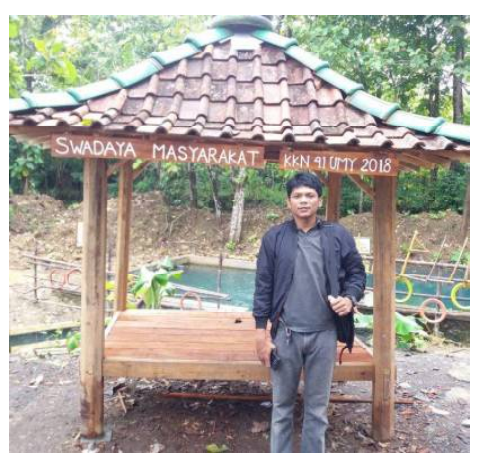

Gambar 10. Gazebo setelah finishing

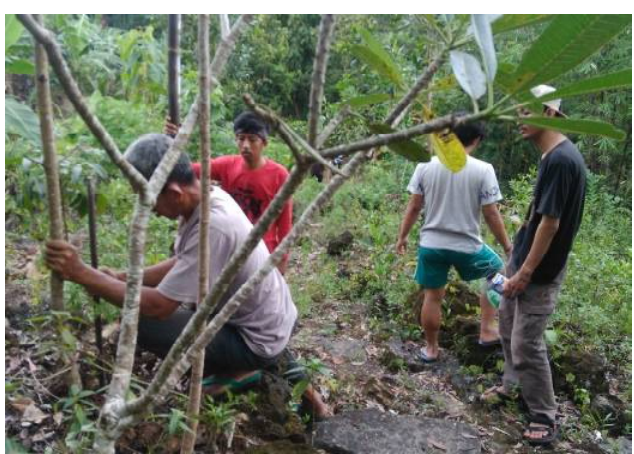

Gambar 12. Merapikan jalan menuju petilasan

tani sehingga masyarakat dapat menjaga kualitas dan kuantitas hasil panennya. $\mathrm{H}$ al ini tentu akan berdampak secara tidak langsung terhadap kualitas produk olahan pertanian. Pelatihan pertama ini menghadirkan pembicara dari Dinas Pertanian yang memang bidang keahliannya di bidang pertanian.

Pelatihan keduadilakukan dengan tujuan memberikan keterampilan pada masyarakat agar peduli kualitas produk makanan yang akan diperjualbelikan. Perizinan P-IRT merupakan salah satu wujud kepedulian terhadap kualitas produk karena P-IRT mampu menunjukkan bahwa produk makanan tersebut layak konsumsi. A danya nomor P-IRT dalam kemasan produk juga akan meningkatkan kepercayaan konsumen akan keamanan produk sehingga konsumen tidak akan khawatir akan kualitas produk bagi kesehatannya. 


\section{d. Pembuatan portal atau website khusus desa Koripan 1 D lingo}

Portal atau website ini dibuat oleh tim bersama dengan pemuda desa sehingga diharapkan masyarakat desa dapat terus menperbaharui isi dari website tersebut. Website ini dapat digunakan sebagai sarana promosi tempat wisata sekaligus sarana pemasaran bagi produk olahan hasil pertanian. Website koripan 1 yang telah dibuat oleh tim dan masyarakat dapat diakses di www.koripan1.wordpress.com.

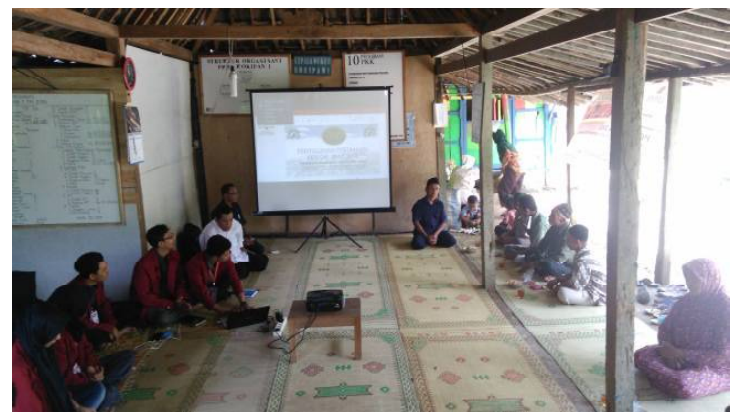

Gambar 13. Penyuluhan pertanian oleh Dinas Pertanian

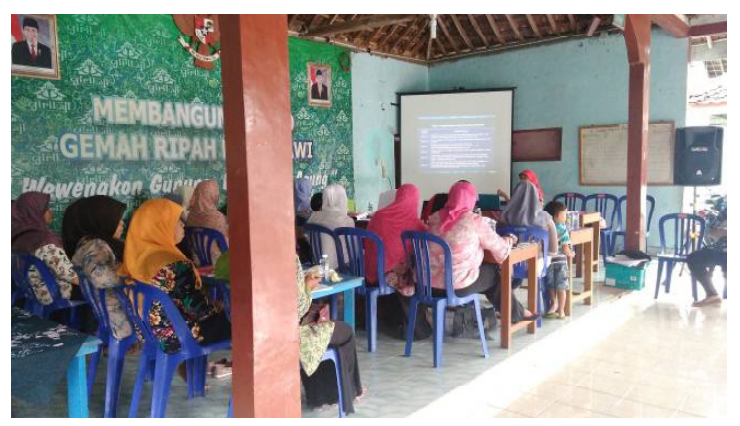

Gambar 15. Penjelasan teknis pengajuan P-IRT oleh Dinas Kesehatan

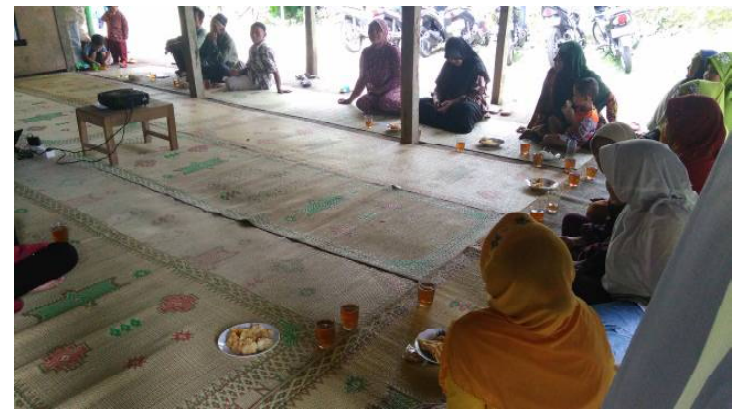

Gambar 14. Masyarakat sebagai Peserta Pelatihan

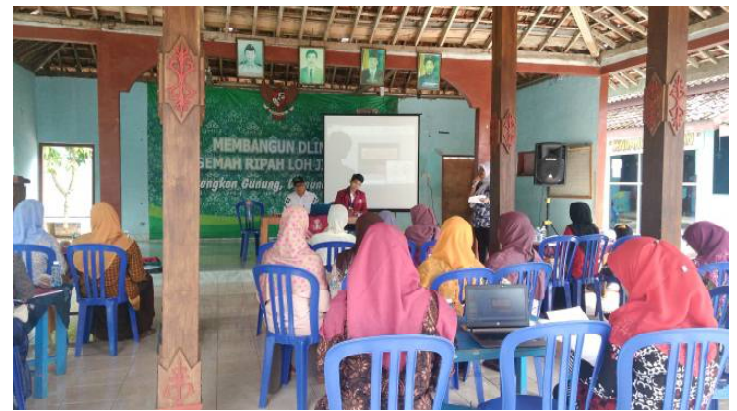

Gambar 16. Pelatihan pentingnya P-IRT

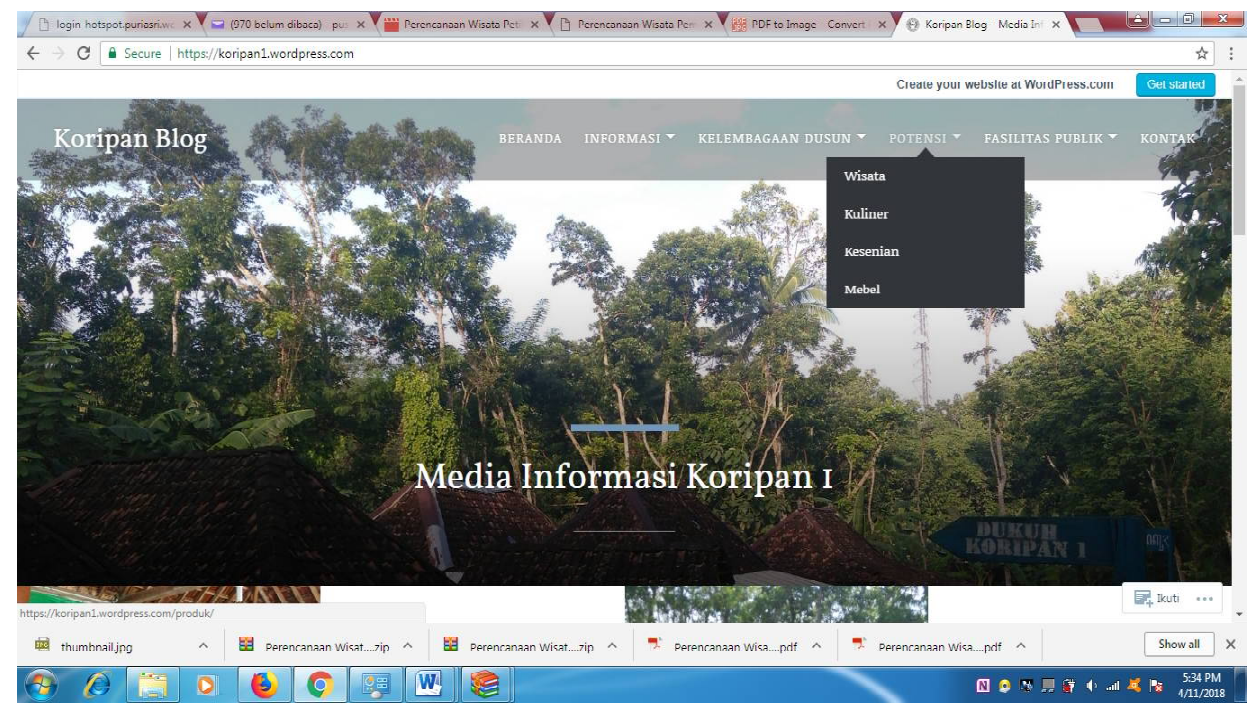

Gambar 17. Halaman muka website Koripan 1 


\section{9}

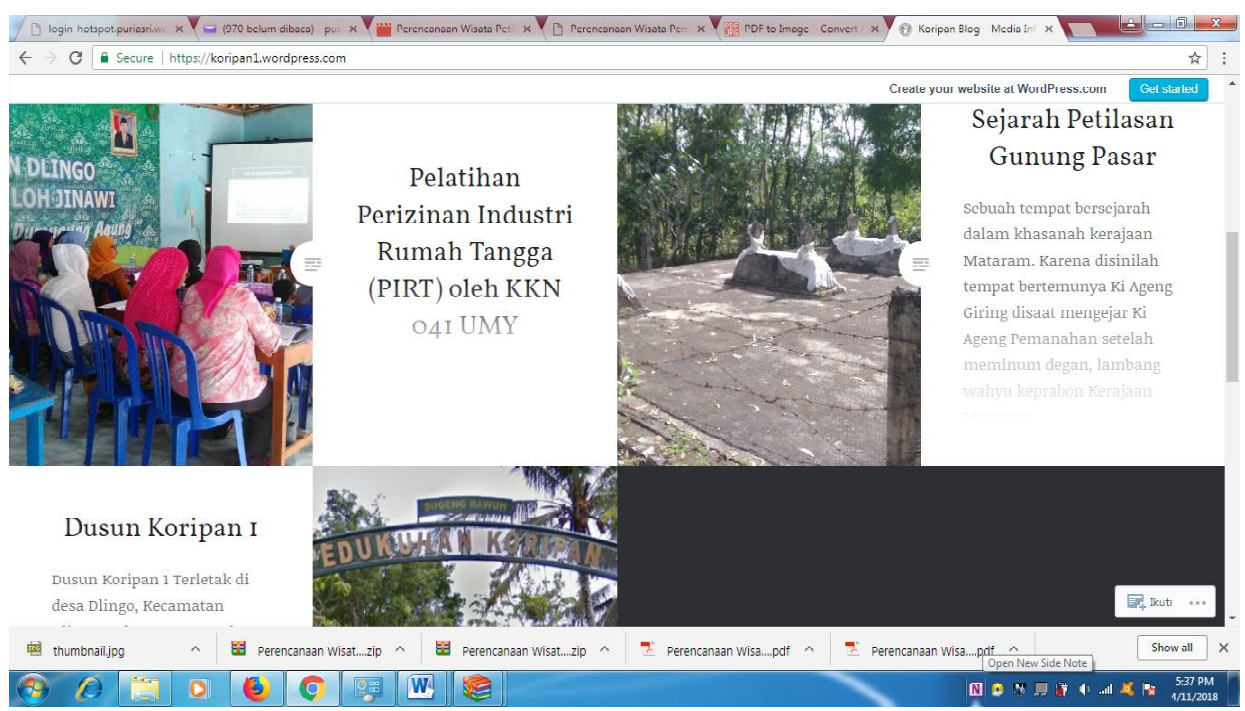

Gambar 18. Tampilan konten website Koripan 1

\section{Tahap 3: pengawasan}

Partisipasi masyarakat dalam tahap pengawasan program pengembangan kawasan wisata dusun Koripan 1 Dlingo baru dilaksanakan dalam tahap kontrol tokoh dan pen ggiat desa dalam pengkondisian masyarakat dan tindakan prefentif terhadap perusakan lingkungan oleh orang asing.

\section{SIM PULAN}

Program pengabdian masyarakat ini telah memberikan solusi dari beberapa permasalahan utama yangdialami dusun Koripan 1 terkait pen gemban gan kawasan wisata. Solusi yang telah dilaksanakan antara lain:

1. D ibuatnya desain pembangunan kawasan wisata Sendang U mbul $N$ deso dan Petilasan Gunung Pasar;

2. Pada tahap pembangunan awal, program ini berhasil menyumbang satu buah gazebo dan perbaikan tempat parkir untuk lokasi wisata Sendang U mbul N deso. Sedangkan sumbangan bagi petilasan Gunung Pasar adalah jalan menuju lokasi petilasan lebih rapi;

3. Teredukasinya masyarakat terkait peningkatan kualitas hasil panen serta tumbuhnya kesadaran serta kemampuan masyarakat dalam men gurus $P \dashv R T$;

4. Dibuatnya website Koripan 1 www.koripan 1.wordpress.com sebagai sarana sosialisasi dan promosi desa Koripan 1 serta pemasaran produknya.

Program ini masih memerlukan pendampingan berkesinambungan demi keberlanjutan program terutama bagi perbaikan dan tata kelola kawasan wisata, peningkatan kualitas 
produk oleh-oleh khas daerah, serta promosi dan pemasaran lokasi maupun produk oleh-oleh.

UCAPAN TERIMA KASIH

Tim Pelaksana pengabdian dalam pengabdian ini mengucapkan banyak terimakasih kepada Pihak Lembaga Pendidikan, Pen elitian dan Pengabdian pada M asyarakat (LP3M) U niversitas M uhammdiyah Yogyakarta sebagai pemberi dana hibah pengabdian kepada Tim Pelaksana.

\section{DAFTAR PUSTAKA}

Dewi, M. H. U., Fandeli, C., \& Baiquni, M. (2013). Pengembangan Desa Wisata Berbasis Partisipasi Masyarakat Lokal di Desa Wisata J atiluwih Tabanan, Ba TABANAN, BALI. Kawistara, 3(2), 129-139.

Dwiputra, R. (2013). Preferensi Wisatawan Terhadap Sarana Wisata di Kawasan Wisata Alam Erupsi Merapi. Jurnal Perencanaan Wilayah Dan Kota, 24(1), 35-48.

Sidiq, A. J., \& Resnawaty, R. (2012). Pengembangan Desa Wisata Berbasis Partisipasi Masyarakat Lokal di Desa Wisata Linggarjati Kuningan, Jawa Barat. In PROSIDING KS: RISET \& PKM (pp. 1140).

Zakaria, F., \& Suprihardjo, R. D. (2014). Konsep Pengembangan Kawasan Desa Wisata di Desa Bandungan Kecamatan Pakong Kabupaten Pamekasan. JURNAL TEKNIK POMITS, 3(2). 